\title{
Long-term degenerative changes in aortic segment homografts, with particular reference to calcification
}

\author{
L O R D B R OCK \\ From the Thoracic Surgical Unit, Guy's Hospital, London, S.E.1
}

\begin{abstract}
The object of this article is to present observations derived from a long-term follow-up (over a period of 8-17 years) of a personal series of aortic segment homografts from which certain important information arises. It will be shown that in those grafts prepared and preserved in a 'fresh' state, calcification has not occurred or has been trivial, whereas in 20 cases in which the graft has been prepared by freeze-drying, calcification is absent in only four, i.e., $21 \%$. Nineteen of these 20 have been traced up to date; only one is so far missing. In spite of calcification the functional result has remained excellent ; in all, the graft was used to replace a segment of aorta resected for aneurysm or for coarctation. The high incidence of aortic wall calcification must assume clinical significance in relation to aortic valve homografting. This procedure is now well established and it is important to consider the future of the valve homograft, especially as most grafts are being prepared by freeze-drying. By analogy from observations on the rate of homografting of aortic segments, calcification is likely to occur at least in that portion of the aortic wall which carries the valve cusps. Impairment of function of the cusps or their involvement in the calcific process seems likely.
\end{abstract}

Freeze-drying as a method of preparation and storage of aortic valve homografts is of great practical convenience. Nevertheless, if calcification of the valve tissue is likely, we must be concerned with long-term results, and it becomes necessary to study the situation critically to see if changes in the methods of preparation and storage are needed. The principle of aortic homografting is so attractive that everything possible should be done to improve its long-term results.

\section{MATERIAL OF THE SURVEY}

In 1951 and 1952 I performed aortic homografting with grafts prepared 'fresh' in balanced salt solution (Gross, Bill, and Peirce, 1949). Three patients have survived-one for 17 years and two for 16 years each. The essential details of these three patients are as follows.

CASE 1 A man aged 31 had a coarctation of the descending thoracic aorta with an accompanying aneurysm which was treated by excision and insertion of a fresh homograft 4 in. $(10 \mathrm{~cm}$.) long and 19 days old. The case was reported in full in 1952 (Brock and Graham, 1952). This patient remains well and 17 years later there is no evidence of calcification of the graft.
CASE 2 A girl aged 17 with a coarctation at the classical site had a fresh homograft eight days old inserted in 1952. She now lives in New Zealand, and I am greatly indebted to Dr. James Lowe and Dr. P. W. Brandt for kindly providing up-to-date information. In January 1967 it was reported that she continued well and that a postero-anterior chest film 'of good quality' showed no significant calcification and it was thought that any calcium would be revealed. Further radiography had to be delayed because she was pregnant.

New radiographs (including penetrating ones) and tomograms in January 1968, 16 years after operation, are reported on by Dr. P. W. Brandt as showing a small linear area of calcification about $0.5 \mathrm{~cm}$. in length in the lateral wall of the descending aorta. A little faint granular calcification is probably present in other portions of the graft'. This'small calcification does not show up well enough to be reproduced as an illustration.

CASE 3 A woman aged 50 underwent resection of a huge aneurysm of the abdominal aorta in October 1952 ; a fresh homograft 18 days old was inserted. Full details of this case and of case 2 were reported in 1953 (Brock, 1953).

She remains well and 16 years later the homograft shows a trivial amount of scattered calcification, far too small to permit reproduction in an illustration. 
In summary, these three patients with fresh grafts fail to show significant or important calcification of the graft.

This is in great contrast to the series of freezedried homografts which were inserted between 1952 and 1959. Twenty patients have survived for followup ; only one patient has not been traced. The shortest follow-up is 9 years, the longest 16 years.

Of these 20 patients, 15 show total calcification of the graft ; in only four is calcification not demonstrable radiologically, that is, $21 \%$ of those traced are not calcified, $79 \%$ are calcified.

\section{DEMONSTRATION OF CALCIFICATION}

Calcification may be obvious radiologically or it may be easily overlooked unless proper care is taken. In many cases a negative report has been received, but further examination has shown total cylindrical calcification. Thus, in a plain posteroanterior radiograph, calcification may not be detected, or perhaps what seems to be a fine linear streak may be revealed on the left side of the graft (Figs 1a and 2b). A lateral radiograph, and especially a penetrating one, may, however, demonstrate severe calcification (Figs $1 \mathrm{~b}$ and $2 \mathrm{~b}$ ). A tomogram may also be conclusive (Fig. 3).

In its final form the calcification has been cylindrical and seems to have affected the whole or the greater part of the graft. In some cases (e.g., Fig. 1b) there is sufficient shading off of each end of the calcified cylinder to suggest that this part may not be grossly affected.
The earliest that calcification has been seen $\overrightarrow{\vec{F}}$ radiologically is four years. Some have shown no calcification after seven years, but it has been present when the patient was re-examined after $\frac{}{\omega}$ 13 years. It is therefore clearly important not $\vec{\nabla}$ to be content with a short-term follow-up ; probably 10 years is the shortest reliable period. The ${ }^{\circ}$ shortest follow-up in this series is eight years, but $\vec{\circ}$

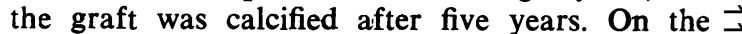
other hand, one patient operated on in 1956 and $\stackrel{\omega}{\sigma}$

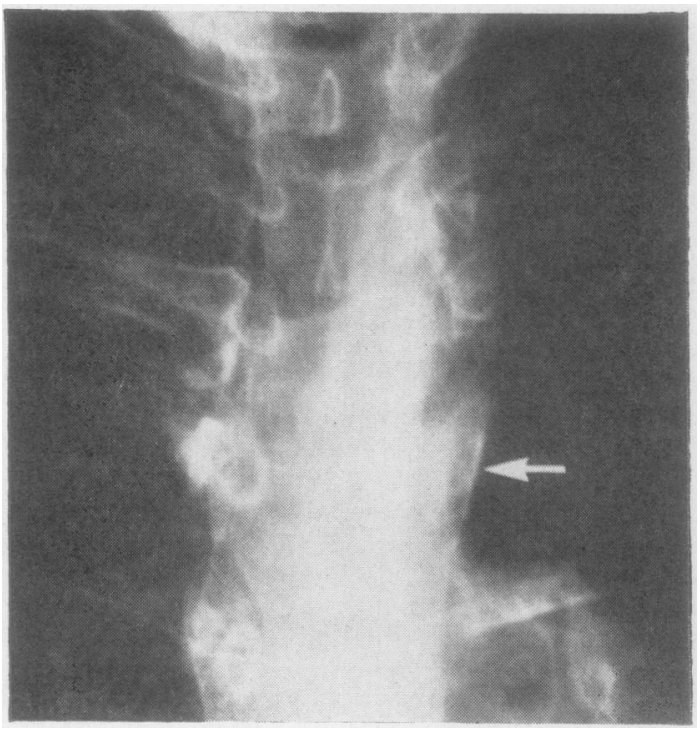

(a)

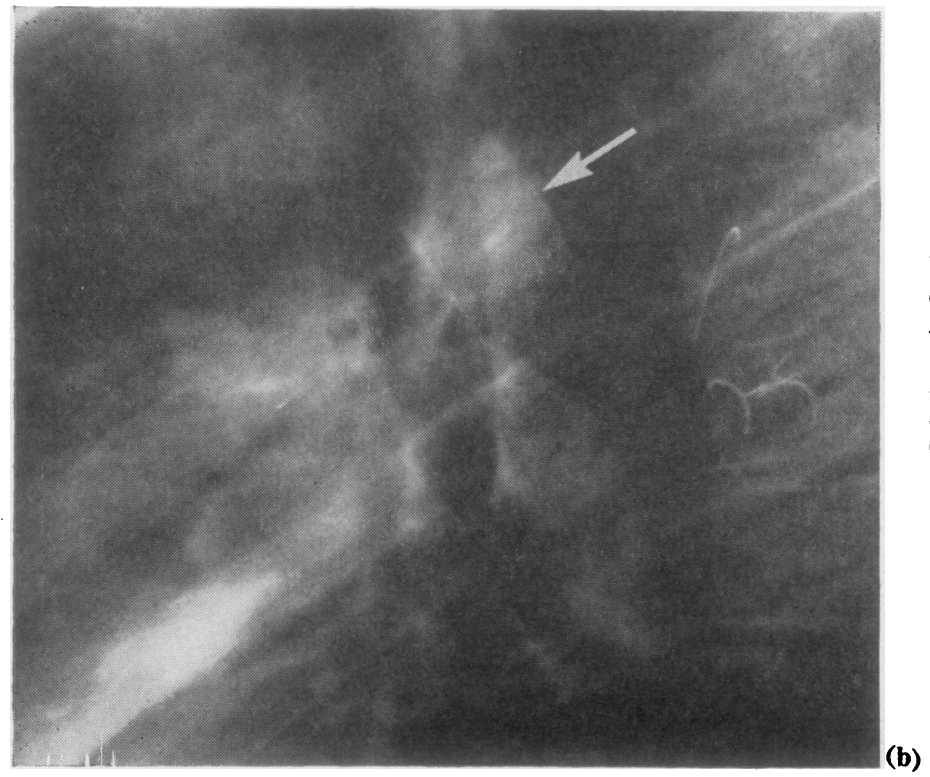

FIG. 1. Penetrating radiographs 15 years after insertion of a freeze-dried homograft. N It is now replaced by a cylinder of calcifi-cation: (a) The sharp, linear left border $N$ is revealed. The outline of the cylinder N is just detectable. In the lateral view (b), the calcified cylinder is clearly shown. 


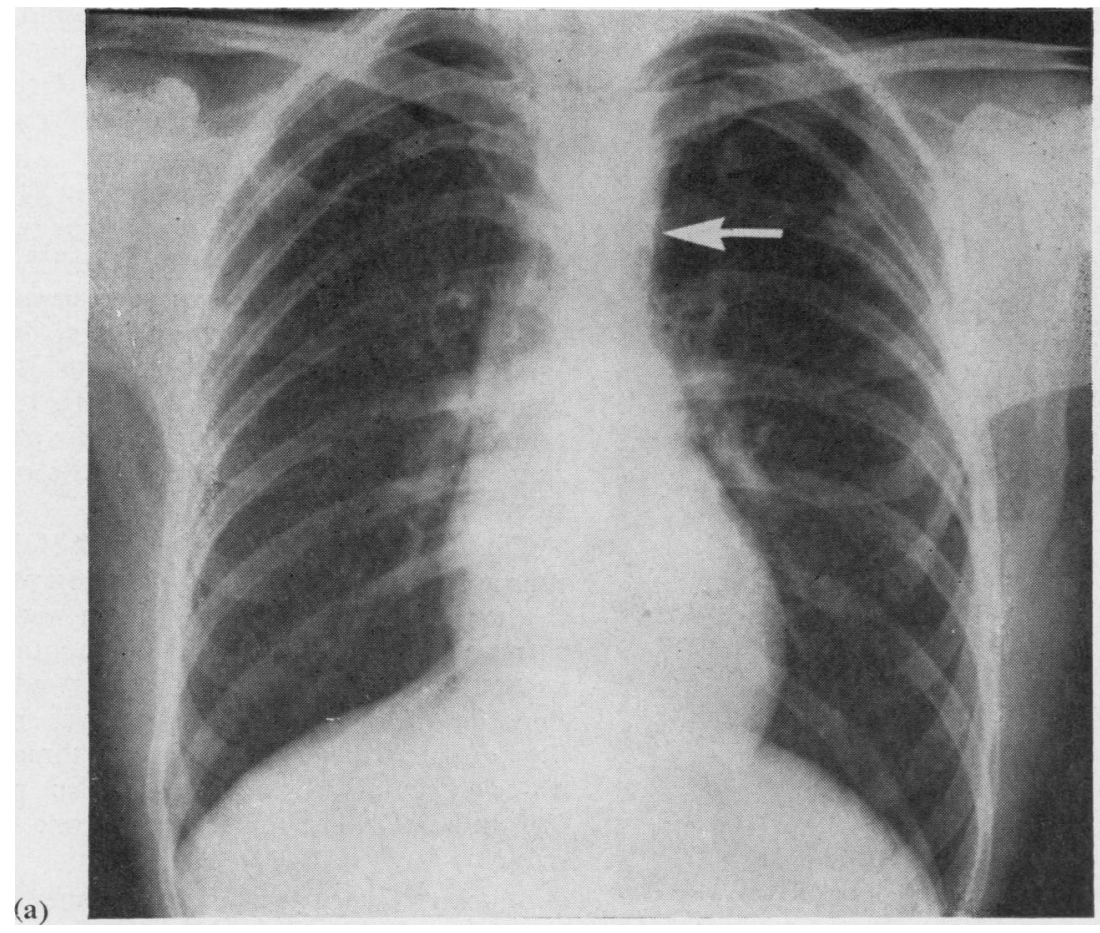

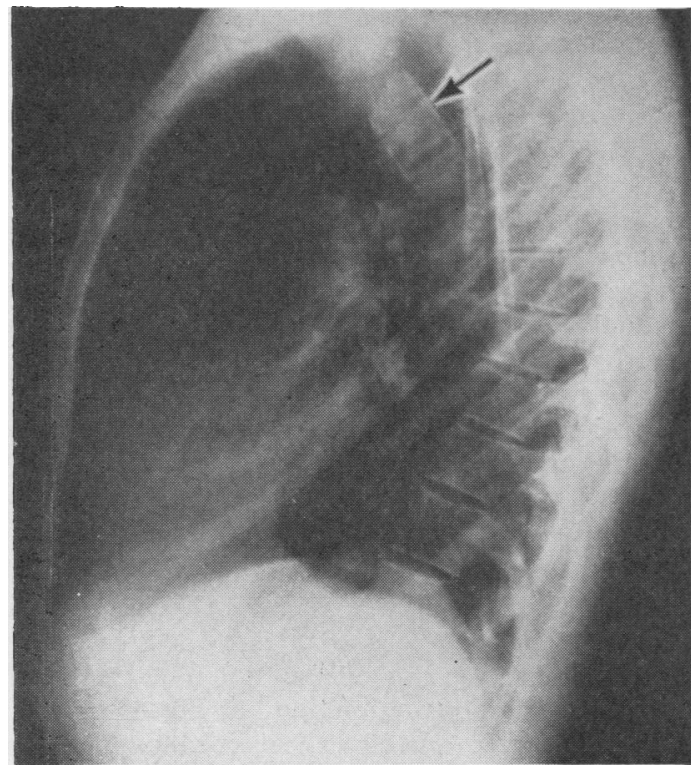

(b)

FIG. 2. Radiographs 11 years after insertion of a freezedried homograft. In the postero-anterior view (a) only a faint linear calcification can be seen immediately below the aortic knuckle, itself not well visualized. In (b) the large calcified cylinder is clearly shown. another in 1957 showed no calcification in 1967 , but perhaps they may yet do so.

It must again be emphasized that radiological exclusion of calcification is not precise unless careful technique is used. Certainly it cannot be excluded by one postero-anterior view of standard penetration.

Radiological demonstration of calcification is obviously a crude way to demonstrate gross calcification. Absence of radiological calcification in the intact body does not necessarily mean that radiography of the graft itself would not reveal calcification and certainly does not exclude its presence on histological examination.

\section{GRAFTS SHOWING NO RADIOLOGICAL CALCIFICATION}

Case 3 , that of resection of a huge abdominal aneurysm and grafting with a fresh graft in 1952, shows trivial scattered calcification, far too small to be reproduced. Other cases of grafts, freezedried, applied to the abdominal aorta have developed calcification; thus a man aged 66 in 1955 had extensive calcification of his graft in 1963.

On the other hand, the cases of freeze-dried grafts not showing calcification include one man aged 61 in 1954 who has no demonstrable calcification in 1967. 


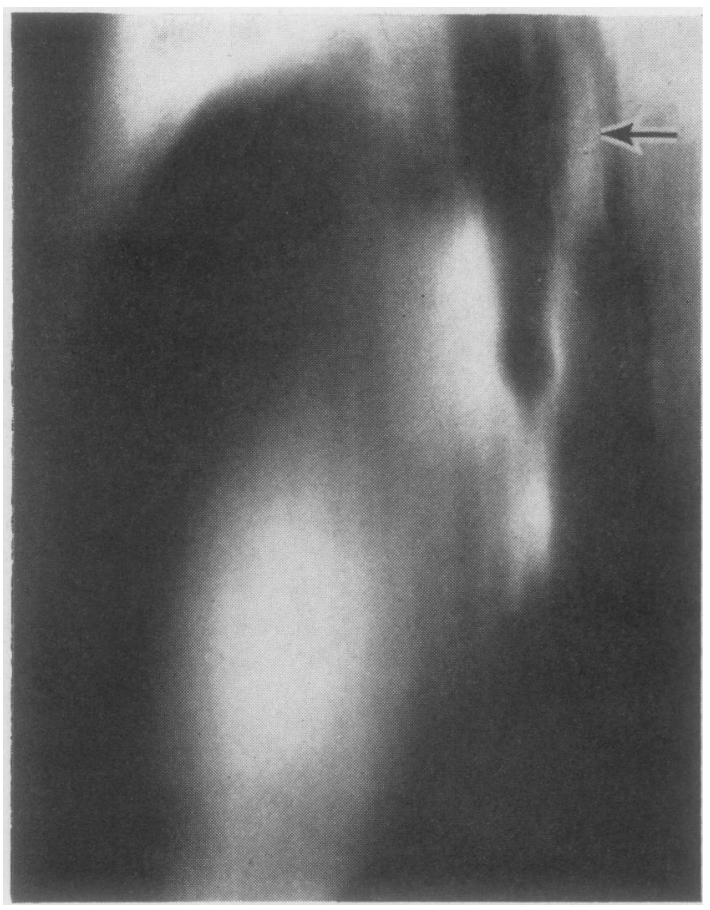

FIG. 3. Lateral tomogram to display the calcified cylinder formed by a freeze-dried homograft inserted 11 years previously. It had not been convincingly displayed on postero-anterior and lateral radiographs.

Three patients who had resection of a coarctation and insertion of a freeze-dried homograft show no calcification after 13,11 , and 10 years.

There is no obvious reason why calcification should not have occurred in these patients.

It must be stressed that the presence of calcification has, up to date, had no significant influence on the clinical result, which in all cases, calcified or non-calcified, has continued to be excellent.

\section{SOURCES OF STUDY IN THE LITERATURE}

Long-term studies of vessel homografting with special reference to calcification are rare, in fact almost non-existent.

Gross, to whose work as a pioneer in this field we owe a great debt, speaking in a discussion in 1954, stated that he had 38 patients alive for periods ranging from two months to six years; in 10 cases the homograft had been in place for more than four years. In three cases mild depositions of calcium were seen on $x$-ray films (Gross, 1954). Gross also stated that 'there can be no doubt that many of the grafts would show pro- $\overrightarrow{\frac{F}{\omega}}$ found histologic changes if they could be examined'. A personal inquiry to Dr. Gross in 1967등 revealed that he had no fuller information about $\overline{\bar{c}}$. late results.

Foster, Collins, Jacobs, and Scott (1965) reporto on 12 patients observed after periods ranging from six to nine years after a freeze-dried homograft.. $\vec{\circ}$ They state that no degenerative changes were seen, $\vec{\overrightarrow{ }}$ but show a lateral radiograph of their longest $\omega$ follow-up case (nine years) in which there is cylindrical calcification of the graft. It is not cer-i tain whether they radiographed their patients care- $\omega$ fully, and the length of follow-up is on the short $\mathrm{w}$ side.

Creech, De Bakey, Cooley, and Halpert (1956)응 report four cases in which a homograft was used. in the abdominal aorta and which were examined 3 at necropsy 14, 24, 28, and 30 months later. All except the 30 -month one showed scattered $\vec{\ominus}$ deposits of calcium. This one was prepared in Tyrode's solution and used after three days. The 14- and 24-month ones were also prepared ino Tyrode's solution; the 28 -month one was freezedried.

Shucksmith, Mitchell, and Zinnemann (1958) report on a freeze-dried homograft used in the abdominal aorta and studied two and a half yearsō later at necropsy; it showed small deposits of 3 calcium.

Pollock, Pratt, and Smiddy (1961) report a 'fresh' graft used in the abdominal aorta which was studied 18 months after insertion because of death from perforation into the duodenum; they found 'small deposits of calcium'. Their survey 3 of the literature showed that 'structural changes gradually occur in the graft and after several months only the elastica of the original donor 0 graft remains .... as the graft ages some fragmentation of the elastica occurs followed by dis $-\frac{7}{0}$ ruption and the formation of cholesterol clefts and calcification'.

The best article is that of Sauvage and Weso- $N$ lowski (1955); it contains a good survey and N్ much original experimental work. Their studies in pigs and dogs revealed that $31 \%$ of freeze-dried grafts showed severe calcification and nearly alle showed some calcification, e.g., 15 out of 16 grafts were calcified in one series, the calcification being slight in three, moderate in seven, and severe in five.

It would be wearisome to present all their官 studies, but these are very informative and should $\frac{\varrho}{O}$ be freely consulted by those interested in the subject of the fate of arterial grafts. 
They found that severe calcification occurred in $100 \%$ of dried homografts. They performed one very interesting experiment in which a standard fresh aortic segment was divided; one half was preserved in Tyrode's solution and one half was freeze-dried. They were then sutured together and implanted as a complete segment. Ten animals came to slaughter after an average time of 228 days.

In no instance did the freeze-dried segment show less calcification than the segment preserved in Tyrode's solution, while in 7 out of $10(70 \%)$ it showed more.

They concluded that a fresh homograft is the best and that study should be directed towards permanently maintaining the viability of homografts.

\section{RELEVANCE TO VALVE HOMOGRAFTING}

Clearly these observations must be relevant to the whole question of valve homografting. The great convenience and technological success of mechanical valves, indeed their great clinical success, should not blind us to their great disadvantages. Homograft replacement offers extra advantages, as should be clearly apparent. It is no part of this article to present the case of the biological approach to the replacement of cardiac valves over the mechanistic approach. Homograft replacement of the aortic and pulmonary valves has been amply demonstrated to be successful by a number of surgeons since Murray's original work (Murray, 1956). Some, like the author, feel strongly that homograft replacement deserves the warmest support.

It is necessary to be realistic and to recognize drawbacks as they emerge. The technical achievement and success of homograft valve insertion has been great, but it will not suffice to rest on this success. If calcification of the homograft is going to occur in a substantial percentage then this cannot be ignored. It is only sensible to anticipate its possible occurrence and the inevitable set-back to the principle of valve homografting that will occur if in a few years' time the valves are found to be unsatisfactory and have to be replaced.

From the observations presented, and especially from the high incidence of severe calcification in my cases here recorded, it seems certain that freeze-dried homografts will not prove satisfactory in the long run.

This does not mean that homograft valve replacement should be abandoned. It means that we must seek out new techniques that will not be followed by degeneration and calcification. This, it will be noted, is the chief conclusion of Sauvage and Wesolowski (1955) - that study should be directed toward permanently maintaining the viability of the homograft.

\section{THE INCIDENCE OF DEGENERATIVE CHANGES IN HOMOGRAFTS}

So far not enough time has elapsed to allow a firm answer to the incidence of severe degenerative changes (especially calcification) in valve homografts, but certain information is available.

Murray (1956) performed his first valve homograft in man in October 1955. The valve was inserted into the first part of the descending aorta and had been preserved in normal saline at $4^{\circ} \mathrm{C}$. for 36 hours. Clinical reports have appeared of progress at eight months, in 1961 and in 1964 (Bigelow, Yao, Aldridge, Heimbecker, and Murray, 1964). Of eight successful operations three deaths occurred between 7 and 14 months later, and in two that came to necropsy the valve was soft and pliable.

The valves in the survivors were still functioning in 1964, the oldest one having been in situ eight and a half years. Dr. Rae Heimbecker (1968) has kindly answered an inquiry and tells me that in three patients, 14,11 , and 8 years since operation, there is still no clinical evidence of valve deterioration and none shows calcification. It must be emphasized that the valves were taken fresh and inserted fresh.

Judith Smith (1967) has given a full and careful report of her study of 53 cases of aortic valve homografts studied at necropsy. The patients had all been operated on by Barratt-Boyes. Her full report should be studied, but her main observation relevant to this article was that five of the grafts showed calcification, the time elapsed since insertion being $15,17,24$, and 29 months. In two cases calcification was in the annulus and was extensive. The 29-month one had a complete ring of calcium.

Because of the slight uncertainty about this calcification some clarification was requested from Dr. Smith, who kindly replied that "calcification was associated with five grafts, and of these the deposits were within the grafted material of four. These had been freeze-dried. In the fifth case the calcification was not in the graft itself but in overlying host lower intimal fibrous sheath'.

Duran, Manley, and Gunning (1965) also found calcification in the donor wall.

Ross (1962) inserted his first homograft valve in 1962. In a recent survey (Ross, 1967a) he states 
that his first patient died four and a half years after operation and the donor aortic wall of the homograft showed considerable calcification. The cusps 'appeared to be largely free from calcium'. It is not clear what this statement means, unless it be that the cusps were partly calcified. Two other patients studied at necropsy after three and a half and two and a half years showed 'fairly heavy calcification' in the donor aortic wall but not in the cusps. Radiographic examination, however, revealed calcium in one cusp of the three-and-ahalf-year case, and Ross makes the interesting suggestion that the incidence of calcification may be determined by ill-fitting cusps, whether immobile or causing turbulence. The occurrence of calcification in congenital bicuspid valves leads him to suggest that a mechanically unfavourable state may predispose to calcification whether the tissue is living or dead.

While it is true that a living valve can calcify, this change takes many years to occur-at least 20 years and often much longer-whereas evidence is certainly strong that a freeze-dried homograft is beginning to calcify after three years.

My colleague, Mr. M. Paneth, has allowed me to quote his experience in two cases which are significant.

In one case a homograft valve was used that had been prepared in buffered formalin. On the tenth day a spike of fever occurred and some regurgitation was noticed. Reoperation was necessary about three and a quarter years later because of regurgitation; the homograft was irregularly calcified and disintegrating and the leaflets contained much pultaceous material.

A second case was a man aged 22 years, who at the age of 15 had had an open relief of congenital aortic stenosis. A second operation was necessary six years later because of regurgitation, and the valve ring was still unusually small. A 2$\mathrm{cm}$. freeze-dried homograft was inserted and did not seem to give an adequate lumen even then; no pressures were taken after its insertion, but a systolic murmur was present from the beginning and persisted. Sixteen months after this operation he presented in left ventricular failure; a pressure difference of $60 \mathrm{~mm}$. $\mathrm{Hg}$ was present between the left ventricle and the aorta; the rate of rise in the aorta was only $300 \mathrm{~mm}$. per second, whereas in the ventricle it was $1,100 \mathrm{~mm}$. $\mathrm{Hg} /$ second.

At reoperation the valve cusps were not fused but were rigid with calcium, chiefly on the aortic aspect. The ring of the aortic homograft wall was also calcified.

In both these cases the early onset of severe calcification seems to have been largely condi $\stackrel{\vec{A}}{\vec{A}}$ tioned by excessive turbulence from an ill-fittingo homograft.

\section{DISCUSSION}

It is certain that if the calcification shown to occur in freeze-dried aortic segments occurs as frequently in freeze-dried aortic valve homografts $\vec{\omega}$ the incidence is too high to be acceptable. The evidence is strong that a similar incidence of calcification does in fact occur in the collar of aortic wall, and evidence is accumulating to sup $\omega$ port the probability of the valve cusps becoming calcified also. If this is so the incidence of failuret of freeze-dried valve homografts will become highe as the years pass.

This does not derogate from the great success of valve homografting, but it must point to the need to anticipate possible lines of failure and to $\overrightarrow{0}$ seek to prevent them. In older patients the calci fication may be of little importance, but its occur:rence must be important in young patients, aso indeed is amply shown in Paneth's cases quoteds above.

The best apparent course would seem to be search for improved methods of maintaining the viability of the graft, thus preventing degenerative $\overrightarrow{\vec{O}}$ changes.

From experience with the three cases in this? series, in which fresh material was used at $4^{\circ} C_{:}^{0}$ in balanced salt solution and in which only trivial calcification or none at all has occurred after 17 , 16 , and 16 years, and from Murray's valve homo-x graft cases preserved in the same way, it appears? that calcification may be avoided.

Even fresh material preserved in this way may show calcification. In most reports this seems to be histological rather than gross radiological, and in Murray's cases the efficiency of the valve has? not been impaired.

We have therefore an important field for con $\widetilde{N}$ tinuing research into improved methods of tissue preservation that will prevent a high incidence of severe degenerative changes. This must be of fundamental importance to the future of homo graft valve replacement.

Difficulties in the harvesting and preservation of valves that may be inseparable from such new techniques should scarcely stand in the way of their use in younger patients.

It was the unsatisfactory behaviour of the freeze-dried homograft that prompted Ross $\mathbb{D}$ (1967b) to introduce the brilliant step of replacingo the aortic valve with an autograft of the pulmonary valve and then replacing the pulmonary 
valve with a freeze-dried homograft. His argument is that an autograft is more likely to be trouble-free for a long time and that degenerative changes in the pulmonary valve might be longer delayed and perhaps not so important as in the aortic valve. The operation is complex and should not displace a method in which fresh homografting of the aortic valve commands a high rate of success.

Ross has also used a pulmonary valve autograft to replace the mitral valve-another important step and one that recognizes that the use of freezedried material is likely to be unsatisfactory in the mitral valve, whether it be a semilunar valve, a mitral homograft, or a heterograft.

On the one occasion on which I have used a freeze-dried mitral valve the cusps were stiff, and this seemed to cause an element of obstruction from the beginning that may have contributed to failure. Certainly the mitral valve would be less tolerant of the onset of degenerative changes that lead to rigidity and calcification.

For this reason, and in an attempt to avoid such changes, I have twice used fresh valve tissue preserved at $4^{\circ} \mathrm{C}$. in B.S.S. for mitral homografting and shall continue to do so.

That the preservation and acceptance of fresh homograft valves may be possible is supported by the work of Mohri, Reichenbach, Barnes, and Merendino (1967), which demonstrated that for as long as four to six months in dogs no rejection occurred of fresh transplanted valve leaflets, and sex chromatin studies suggested that partial substitution of the donor valve with host cells may occur. The valve tissue seems more acceptable and less liable to rejection than certain other tissues. These observations are very significant and could be of fundamental importance in future valve replacement techniques.

Urist and Adams (1967) have also reported on factors that influence calcification in transplants of the aorta as a result of their experiments of implanting aortic fragments into the anterior chamber of the eye in rats. They demonstrate that age is important as well as various physical and chemical properties of the implant. Their study includes pretreatment of the aortic implants to find if this could check or prevent the tendency to calcification. This work on chemical factors influencing the incidence of calcification is clearly of great potential importance and demands further inquiry. It could be very convenient if serious degenerative changes in a graft can be prevented by chemical adjustment, but the primary superiority of living over dead graft tissue would not seem to be severely affected by such a procedure.

\section{REFERENCES}

Bigelow, W. G., Yao, J. K., Aldridge, H. E., Heimbecker, R. O., and Murray, G. D. W. (1964). Clinical homograft valve transplantaMurray, G. D. W. (1964). Clinical homogsaf
tion. J. thorac. cardiovasc. Surg., 48, 333 .

Brock, R. C. (1953). Aortic homografting. Guy's Hosp. Rep., 102, 204.

- and Graham, A. J. P. (1952). Resection of combined aneurysm and coarctation of the aorta with insertion of a homograft. Ibid., 101, 207.

Creech, O., De Bakey, M. E., Cooley, D. A., and Halpert, B. (1956). Structural alterations in human aortic homografts one to two and one-half years after transplantation. Surg. Gynec. Obstet.,
103,147 .

Duran, C. G., Manley, G., and Gunning, A. J. (1965). The behaviour of homotransplanted aortic valves in the dog. Brit. J. Surg., $52,549$.

Foster, J. H., Collins, H. A., Jacobs, J. K., and Scott, H. W. (1965). Long term follow-up of homografts used in the treatment of coarctation of the aorta. J. cardiovasc. Surg. (Torino), 6, 111.

Gross, R. E. (1954). In the discussion of a paper by Creech, $O$. De Bakey, M. E., Self, M., and Halpert, B. (1954). The fate of heterologous arterial grafts: an experimental study. Surgery,
36, 431 .

Bill, A. H., and Peirce, E. C. (1949). Methods for preservation and transplantation of arterial grafts. Surg. Gynec. Obstet.,

Heimbecker, R. O. (1968). Personal communication.

Mohri, H., Reichenbach, D. D., Barnes, R. W., and Merendino, K. A. (1967). A biologic study of the homologous aortic valve in dogs. J. thorac. cardiovasc. Surg., 54, 622.

Murray, G. (1956). Homologous aortic-valve-segment transplants as surgical treatment for aortic and mitral insufficiency. Angiology, Paneth, M. (1968). Personal communication.

Pollock, A. V., Pratt, D., and Smiddy, F. G. (1961). Aortic homograft replacement: a sequel. Ann. Surg., 153, 472.

Ross, D. N. (1962). Homograft replacement of the aortic valve. Lancet, $2,487$. Surg., 54, 842.

- (1967b). Replacement of aortic and mitral valves with a pulmonary autograft. Lancet, $2,956$. Sauvage, L. R., and Wesolowski, S. A. (1955). The healing and fate
of arterial grafts. Surgery, 38, 1090 .

Shucksmith, H. S., Mitchell, W. M., and Zinnemann, K. (1958). Two and a half years' survival of a grafted abdominal aortic aneurysm with histological studies. Brit. J. Surg., 46, 141. Smith, J. C. (1967). The pathology of human aortic valve homografts.
Thorax, 22, 114.

Urist, M. R., and Adams, J. M. (1967). Localization mechanism of calcification in transplants of aorta. Ann. Surg., 166 : 1 . 